\title{
COMMENTAR Y \\ Training generalist doctors for rural practice in New Zealand
}

\author{
G Nixon ${ }^{1}, \mathrm{~K}$ Blattner ${ }^{1}, \mathrm{M}$ Williamson ${ }^{1}, \mathrm{P}_{\mathrm{McHugh}}{ }^{2} \mathrm{~J} \mathrm{Reid}^{2}$ \\ ${ }^{1}$ University of Otago, Dunedin, New Zealand \\ ${ }^{2}$ Royal New Zealand College of General Practitioners, Wellington, New Zealand
}

Submitted: 10 June 2016; Accepted: 29 November 2016; Published: 8 March 2017

Nixon G, Blattner K, Williamson M, McHugh P, Reid J

Training generalist doctors for rural practice in New Zealand

Rural and Remote Health 17: 4047. (Online) 2017

Available: http://www.rrh.org.au

A B S T R A C T

Targeted postgraduate training increases the likelihood young doctors will take up careers in rural generalist medicine. This article describes the postgraduate pathways that have evolved for these doctors in New Zealand. The Cairns consensus statement 2014 defined rural medical generalism as a scope of practice that encompasses primary care, hospital or secondary care, emergency care, advanced skill sets and a population-based approach to the health needs of rural communities. Even as work goes on to define this role different jurisdictions have developed their own training pathways for these important members of the rural healthcare workforce. In 2002 the University of Otago developed a distance-taught postgraduate diploma aimed at the extended practice of rural general practitioners (GPs) and rural hospital medical officers. This qualification has evolved into a 4-year vocational training program in rural hospital medicine, with the university diploma retained as the academic component. The intentionally flexible and modular nature of the rural hospital training program and university diploma allow for a range of training options. The majority of trainees are taking advantage of this by combining general practice and rural hospital training. Although structured quite differently the components of this combined pathway looks similar to the Australian rural generalist pathways. There is evidence that the program has had a positive impact on the New Zealand rural hospital medical workforce.

Key words: generalism, New Zealand, postgraduate, rural hospital, training.

(C) G Nixon, K Blattner, M Williamson, P McHugh, J Reid, 2016. A Licence to publish this material has been given to James Cook University, http://www.jcu.edu.au 
In New Zealand a unique set of postgraduate pathways has evolved to train rural medical practitioners in extended scopes of generalist practice. This article describes these pathways and the history of their development.

Rural generalist medicine is seen as an essential component in the delivery of comprehensive and equitable health care to rural communities in an age of subspecialisation and centralisation $^{1}$. The 2014 Cairns consensus statement on rural generalist medicine defined rural generalist medicine as a broad scope of rural medical care that encompasses comprehensive primary care, hospital or secondary care, emergency care and advanced skill sets ${ }^{1}$. It emphasises population health and multidisciplinary team approaches that align, and are responsive to, the health needs of rural communities.

A second meeting on rural generalist medicine was held in Montreal in 2015 where the concept was endorsed, but it was agreed that the model might not be the same everywhere $^{2}$. A task group has been formed to progress a strategic research framework and establish international collaborations for this work. A further meeting is planned prior to the WONCA Rural Health Conference in April 2017 in Cairns.

The Cairns consensus calls for dedicated rural generalist training programs ${ }^{1}$. The first of these was developed in Queensland in $2005^{3}$. Other Australian states have followed ${ }^{4}$. Recently Queensland broadened the concept to include the training of allied health professionals ${ }^{5}$. Current evidence suggests that targeted training for rural practice at the postgraduate level, along with rural origin and positive exposure to rural health in the undergraduate years, are the factors most strongly associated with entering rural practice ${ }^{6}$.

There are currently 26 hospitals in New Zealand that meet the Medical Council of New Zealand definition of a rural hospital $^{7}$. These hospitals have a predominantly generalist medical workforce and are geographically distant from a base hospital.
The New Zealand health reforms of the 1990s resulted in the centralisation of services and the withdrawal of specialists from rural hospitals (a process that is continuing) ${ }^{8}$. This placed a further burden on rural general practice which was facing its own workforce shortage 9 . The absence of a targeted rural general practice training program compounded the problem $^{10-12}$. As a consequence rural hospitals became increasingly reliant on doctors who had not undertaken vocational training and had no affiliation with a professional college $^{13}$. Standards of care became inconsistent and a chronic workforce shortage developed ${ }^{13}$. By 2009 one-third of rural hospital medical positions were vacant, there was a high turnover and international medical graduates made up $68 \%$ of the workforce. Seventy-five percent of rural hospital managers described the medical staff shortage as serious or critical $^{13}$.

The first initiative to try to improve the situation was the establishment of the Postgraduate Diploma in Rural and Provincial Hospital Practice (PGDipRPHP) by the Department of General Practice, Dunedin School of Medicine, University of Otago in 2002. This distance-taught qualification was aimed at rural general practitioners and rural hospital doctors wishing to undertake relevant study while continuing in practice. At its inception the PGDipRPHP included three distance-taught papers: Medicine, Surgery and Rural Context. The aim was to upskill the rural hospital workforce and to build a cadre of rural hospital generalists who would define and develop the scope of practice and build the clinical and academic capacity needed to support it.

Building on the relationships that were forged while participating in the PGDipRPHP, representatives from the country's rural hospital medical workforce held their first formal meeting in 2005. A working party was formed, made up of both rural general practitioners and full-time hospital doctors, with the aim of addressing the professional and training issues which were seen as a major barrier to resolving the rural hospital and, ultimately, rural generalist workforce shortage ${ }^{14}$. 
In 2008, as a result of the recommendations this working party made to the Medical Council of New Zealand, rural hospital medicine was recognised as a new scope of practice, the Royal New Zealand College of General Practitioners (RNZCGP) created a Division of Rural Hospital Medicine, and the Clinical Training Agency (now Health Workforce New Zealand) allocated funding for a Rural Hospital Medicine Training Program (RHMTP) ${ }^{14,15}$.

The RNZCGP Division of Rural Hospital Medicine established a valuable and productive relationship with the Australian College of Rural and Remote Medicine (ACRRM). The RHMTP was supported in its development through access to the ACRRM curriculum and the ACRRM assessment tools.

Embracing from the outset the full breadth of rural medical generalism, as later defined at Cairns, appears to have been a key decision. The creation of a new scope of practice has brought the rural workforce together and created a range of interrelated career pathways for rural generalist doctors ${ }^{14,15}$. It brought those doctors without vocational training into the RNZCGP and provided them with a vocational scope, professional structure and training. At the same time it recognised, and supported, the extended scope being practised by many rural general practitioners who were already members of the RNZCGP.

The key principles that underpin the success of the new 4year RHMTP are recognition of prior learning, competencebased assessment and a modular (rather than linear) pathway. The clinical attachments and academic modules can be completed in any order, in different parts of the country and within a flexible timeframe. This flexibility is not only important for integration with other programs; it is less onerous for trainees, as they move between rural and urban attachments.

Many trainees have embraced the flexibility although some have found the absence of a linear pathway and the multiple options challenging. In particular they have had difficulty accessing funded training posts in some specialties, including rural general practice ${ }^{7}$. Some district health boards have decided to offer all the clinical attachments in a single region in an attempt to provide greater certainty for trainees and stabilise their own rural workforce.

The recognition of prior learning extends to both clinical and academic modules. This can include time spent on other training programs, relevant previous clinical attachments and other university and professional college qualifications and examinations. It avoids unnecessary duplication, reducing costs for both trainee and state funders. It frees up time that can be dedicated to the acquisition of advanced skill sets.

The RHMTP is proving popular with 26 applicants for the 10 available positions in 2015. Fifteen trainees have been awarded fellowships.

Some trainees undertake the RHMTP alone or in combination with emergency medicine or internal medicine. These doctors are looking at full-time hospital careers managing inpatients and emergency department presentations. Their focus is at the secondary care end of the rural generalism spectrum and they are likely to work in larger rural hospitals. These trainees still require a minimum of 6 months of rural general practice during their training.

Seventy-five percent of trainees are choosing to combine the RHMTP with GP training ${ }^{7}$. It is this combined pathway, Dual Fellowship, that is similar to the Australian rural generalist pathways. It is likely this considerable cohort will cement the future of the New Zealand rural generalist. Dual Fellowship has necessitated considerable flexibility on the part of both training programs, which has been achieved without reducing clinical experience or academic standards. The GP and the RHMTP cross-credit components of the other training program, both clinical attachments and academic modules. Each maintains its separate assessment processes. It is possible to complete Dual Fellowship in 4 years although many trainees will take an additional year. On successfully completing their training these doctors receive fellowships in both general practice (FRNZCGP) and rural hospital medicine (FDRHMNZ). The components of a typical Dual 
Fellowship, both clinical attachments and academic modules, are outlined in Table 1.

The academic component of GP training is delivered by the RNZCGP through the General Practice Education Programme (GPEP1) regional seminar program. Forty days of education are spread over 12 months, focusing on community-based primary care. Rural trainees usually travel to the nearest urban centre for the seminars which are attended by all GP trainees. Clinical attachments in rural general practice provide the rural specific component of this program.

The academic modules for rural hospital training are delivered by the universities and principally the University of Otago PGDipRPHP that now sits in the Dunedin School of Medicine. The dispersed student body taught by an equally dispersed faculty is unique in the University of Otago and supporting them has proven a challenge for the centralised university structure. The three PGDipRPHP papers were converted into seven mostly smaller papers in 2009. These modules align with the program's provision for recognition of prior learning and provide more effective coverage of the RHMTP curriculum.

All papers are distance taught. Components include videoconferencing (Zoom Videoconferencing) and an internet-based interactive teaching platform (Moodle Learning Management System). Face-to-face residential workshops remain an essential component. There is one residential per paper ranging in length from 4 to 6 days. For trainees, many of whom will be the only rural trainee in their current place of work, the residential components provide an important opportunity to engage with their peers and their teachers face to face. Class size is limited to 20 students.

The papers that make up the PGDipRPHP are listed in Table 1. Topics covered in the Context paper include rural health inequalities, living and working in rural communities, teamwork, governance, teaching and research. The Communication paper has developed a strong relationship with a rural Maori community in New Zealand's far north.
The residential is held on a local marae (meeting ground), the immersion providing a powerful learning experience. Topics covered include health and socioeconomic health inequalities, communication as well as palliative care and mental health. The Trauma and Emergencies paper makes use of hi-fidelity simulation at the Christchurch Hospital simulation laboratory.

The PGDipRPHP papers are also open to other rural doctors wishing to continue their medical education or upskill in specific aspects of rural generalist practice. The ability of these experienced rural doctors to link the learning to the realities of rural practice adds greatly to the educational experience of the vocational trainees in the same class.

The papers are convened by experienced and clinically active rural doctors who have an interest or expertise in the topic being taught. Hospital specialists are involved as resource experts, rather than in the delivery of didactic teaching. Much of the learning is small group and case-based with a strong emphasis on the rural context. Enrolments in papers have risen steadily, from 12 in 2006 to 79 in 2015.

Early indications are that that the initiatives outlined in this article are having a positive impact on the New Zealand rural hospital workforce. The vacancy rate for rural hospital positions decreased from 33\% in 2009 to 6\% in 2015, and the percentage of hospital managers reporting a serious or critical shortage of medical staff has dropped from $75 \%$ in 2009 to $25 \%$ in $2015^{7}$.

Rural hospital medicine training may be attracting trainees at the expense of rural primary care and there is a risk that rural practices not associated with a hospital may be disadvantaged in the long term. Because of this, options for targeted rural GP training are being considered by the RNZCGP. One possibility is the recognition of an 'advanced core competency' in rural general practice, gained by completing some, but not all, of the modular components of the RHMTP. A rural advanced core competency could be converted into a full Dual Fellowship if desired at a later date and in a way that further aligns rural training options ${ }^{16}$. 
Table 1: Components of dual general practice and rural hospital medicine training pathway for a typical trainee

\begin{tabular}{|c|c|}
\hline Training attachments & Academic components \\
\hline $\begin{array}{l}\text { Supervised (rural) general practice training: } 1 \text { year (GPEP1) } \\
\text { Additional unsupervised general practice: } 6 \text { months }\end{array}$ & GPEP1 seminars: 40 days \\
\hline $\begin{array}{l}\text { Hospital attachments at registrar level } \\
\text { Internal medicine } \mathrm{e}^{\dagger}: 6 \text { months } \\
\text { Emergency medicine } \mathrm{e}^{\dagger}: 6 \text { months } \\
\text { Paediatrics }^{\dagger}: 3 \text { months } \\
\text { Anaesthetics or intensive care } \mathrm{e}^{\dagger}: 3 \text { months } \\
\text { Rural hospital attachments: } 2 \mathrm{x} 6 \text {-month attachments } \\
\text { Advanced skill/elective training: } 6 \text { months to } 1 \text { year }\end{array}$ & $\begin{array}{l}\text { PGDipRPHP papers: } \\
\text { - Rural context } \\
\text { - Communication } \\
\text { - Medical specialties } \\
\text { - } \quad \text { Obrgical specialties } \\
\text { - Cardiology and respiratory medicine } \\
\text { - Emergency medicine } \\
\text { - Early Management of Severe Trauma Course } \\
\text { - Advanced Paediatric Life Support Course } \\
\text { - Advanced Cardiac Life Support Course (New Zealand } \\
\text { Resuscitation Council level 7) }\end{array}$ \\
\hline
\end{tabular}

This article adds to existing knowledge by describing the structure and evolution of the rural hospital medicine training program in New Zealand, highlighting the key features of its success. These include integration with existing general practice training and linking vocational training with a postgraduate university qualification.

New Zealand's rural population is spread thinly over a terrain that is not vast but is rugged. Also, its institutions and communities of interest are relatively small. This differs from the rural population and geography of Canada and Australia, the countries that have taken the lead in the debate on rural generalism $^{1}$. The generalist rural medical training pathways that have grown organically in the New Zealand environment may thus be well suited to its needs.

\section{Acknowledgements}

We wish to acknowledge the substantial efforts of the late Dr Pat Farry in establishing the inaugural course and the debt that rural generalism owes this tireless advocate.

\section{References}

1. Murray R. Cairns consensus statement on rural generalist medicine. (Internet) 2013.v Available: http://www.ruralgeneralismsummit. net/cairns-consensus-statement-on-rural-generalist-medicine.

(Accessed 8 February 2017).

2. Rural Generalist Medicine Working Group. Summary outcome report. 2nd World Summit on Rural Generalist Medicine 2015. Montreal: Society of Rural Physicians Canada, 2015.

3. Kitchener S. Rural generalism and the Queensland Health pathway - implications for rural clinical supervisors, placements and rural medical education providers. Rural and Remote Health (Internet) 2013; 13(2359). Available: www.rrh.org.au (Accessed 8 February 2017).

4. Australian College of Rural and Remote Medicine. Rural generalist program providers. (Internet). Available: http://www. acrrm.org.au/preparing-for-your-career/rural-generalist-programs /rural-generalist-program-providers (Accessed 8 February 2017). 
5. Queensland Health. Allied health rural generalist training positions: 2014 implementation report. (Internet) 2015. Available: https:// www.health.qld.gov.au/ahwac/ (Accessed 8 February 2017).

6. Strasser R, Couper I, Wynn-Jones J, Rourke J, Chater AB, Reid S. Education for rural practice in rural practice. Education for Primary Care 2016; 27(1): 10-4. https://doi.org/10.1080/14739879. 2015.1128684

7. Lawrenson R, Reid J, Nixon G, Lawrenson A. The New Zealand Rural Hospital Doctors Workforce Survey 2015. New Zealand Medical Journal 2016; 129(1434): 7.

8. Gauld R. Beyond New Zealand's dual health reforms. Social Administration and Policy 1999; 33(5): 18. https://doi.org/ $10.1111 / 1467-9515.00171$

9. Janes R, Dowell A, Cormack D. New Zealand Rural General Practitioners 1999 Survey - Part 1: an overview of the rural doctor workforce and their concerns. New Zealand Medical Journal 2001; 114(1143): 3 .

10. London $M$. The future of rural general practice in New Zealand. New Zealand Medical Journal 2004; 117(1191).
11. Burton J. Rural health care In New Zealand. Occasional paper no. 4. Wellington: Royal New Zealand College of General Practitioners, 1999.

12. Burton J. Difficulties encountered in rural general practice in New Zealand. New Zealand Family Physician 1997; 24: 41-44.

13. Lawrenson R, Nixon G, Steed R. The rural hospital doctors workforce in New Zealand. Rural and Remote Health (Internet) 2011; 11(1588). Available: www.rrh.org.au (Accessed 8 February 2017).

14. Nixon G, Blattner K. Rural hospital medicine in New Zealand: vocational registration and the recognition of a new scope of practice. New Zealand Medical Journal 2007; 120(1259): 5.

15. Nixon G, Blattner K. Recent developments in rural hospital medicine I: rural hospital medicine special scope. New Zealand Family Physician 2008; 35(6): 402-404.

16. Royal New Zealand College of General Practitioners. Rural general practice in 2015. Education, recruitment, retention and standards. (Internet) 2016. Available: https://www.rnzcgp.org.nz/ RNZCGP/Publications/The_GP_workforce/RNZCGP/Publicatio ns/GP_workforce.aspx?hkey=a7341975-3f92-4d84-98ec-

8c72f7c8e151 (Accessed 8 February 2017).

(C) G Nixon, K Blattner, M Williamson, P McHugh, J Reid, 2016. A Licence to publish this material has been given to James Cook University, http: / /www.jcu.edu.au 